\title{
Therapeutic effects of neurotrophic factors in experimental spinal cord injury models
}

\author{
This article was published in the following Dove Press journal: \\ Journal of Neurorestoratology \\ 23 March 2016 \\ Number of times this article has been viewed
}

\author{
Mitsuhiro Enomoto ${ }^{1,2}$ \\ 'Department of Orthopaedic and \\ Spinal Surgery, Graduate School, \\ ${ }^{2}$ Hyperbaric Medical Center, Tokyo \\ Medical and Dental University, Tokyo, \\ Japan
}

\begin{abstract}
Neurotrophic factors (NFs) play important roles in regenerative medicine approaches to mitigate primary and secondary damage after spinal cord injury (SCI) because their receptors are still present in the injured spinal cord even though the expression of the NFs themselves is decreased. Several reports have shown that NF administration increases regenerative signaling after SCI, particularly by stimulating axonal growth. However, few NFs cross the blood-brain barrier, and most of them show low stability and limited diffusion within the central nervous system. To overcome this problem, transplantation strategies using genetically modified NFsecreting Schwann cells, neural and glial progenitor cells, and mesenchymal stem cells have been applied to animal models of SCI. In particular, multifunctional NFs that bind to TrkB, TrkC, and p75NTR receptors have been discovered in the last decade and utilized in preclinical cell therapies for spinal cord repair. To achieve functional recovery after SCI, it is important to consider the different effects of each NF on axonal regeneration, and strategies should be established to specifically harness the multifunctional properties of NFs. This review provides an overview of multifunctional NFs combined with cell therapy in experimental SCI models and a proposal to implement their use as a clinically viable therapy.
\end{abstract}

Keywords: spinal cord injury, neurotrophic factor, multineurotrophin, regeneration, cell transplantation

\section{Introduction}

Neurotrophic factors (NFs) such as nerve growth factor (NGF), brain-derived neurotrophic factor (BDNF), and glial cell-derived neurotrophic factor (GDNF) play important roles in promoting functional recovery following spinal cord injury (SCI) through either neural protection or neural regeneration. Specific NFs that stimulate axonal growth have different effects on axonal regeneration after injury through a variety of cellular mechanisms. ${ }^{1}$ For example, sympathetic neurons and sensory neurons depend on NGF for survival, and surprisingly, robust growth of responsive axons is observed after NGF delivery by gene transfer into the injured spinal cord even long after the injury. ${ }^{2}$ BDNF has been shown to reverse atrophy of rubrospinal neurons after axotomy. ${ }^{3}$ Neurotrophin-3 (NT-3) has been shown to prevent cell death and reduce atrophy in spinal cord projection neurons. ${ }^{4}$ BDNF and NT-3 have also been shown to reduce axonal degeneration and induce sprouting of corticospinal axons. ${ }^{2,5,6}$ Given these different mechanisms, the use of multiple NFs or NFs with multimodal activity may be necessary for restoring coordinated locomotion. One of multineurotrophins (MNTs), D15A, has been found to bind and activate TrkB, TrkC, and p75NTR. ${ }^{7}$ Additionally, the appropriate administration route for NFs to effectively reach the injury environment
Correspondence: Mitsuhiro Enomoto Hyperbaric Medical Center, Tokyo Medical and Dental University, I-5-45 Yushima, Bunkyo-ku, Tokyo II 3-85 I9, Japan

Tel +8I 358035279

Fax $+8 \mid 35803528$ I

Email enomorth@tmd.ac.jp
Journal of Neurorestoratology 2016:4 I5-22

(c) (1) (8) ๑ 2016 Enomoto. This work is published and licensed by Dove Medical Press Limited. The full terms of this license are avaialable at https:/www.dovepress.com/terms.php cc. hereby accept the Terms. Non-commercial uses of the work are permitted without any further permisision from Dove Medical Press Limited, provided the work is properly atributed. For peminsion for commercial use of this work, please see paragraphs 4.2 and 5 of our Terms (htpps://www.dovepress. com/terms.php).
Dovepress

http://dx.doi.org/10.2147/JN.S66874

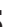
(1) 
should be carefully considered because few NFs cross the blood-brain barrier and they are characterized by low stability and limited diffusion in the central nervous system. ${ }^{8}$ To address these issues, cell therapy where NFs are released from transplanted cells or host cells has been proposed as a promising strategy for SCI, ${ }^{9,10}$ and various NF-producing cells such as fibroblasts, Schwann cells (SCs), neural progenitor cells (NPCs), mesenchymal stem cells (MSCs), and bone marrow stromal cells (BMSCs) have been transplanted to increase neurotrophic signaling in the injured spinal cord. ${ }^{11-13}$ For example, SCs are frequently used as a cellular source of transplants, and in vitro-expanded SCs have been shown to endogenously produce numerous NFs. ${ }^{14}$ MNT-producing SCs generated using genetic engineering have been reported to regenerate injured spinal cord tissue. ${ }^{15-19}$ The current review provides an overview of the role of NFs delivered by cell therapy in experimental SCI models and a proposal to implement their use as a viable clinical therapy.

\section{NF receptors and their expression after SCI}

NGF, BDNF, NT-3, and neurotrophin-4 were originally classified as neurotrophins, and their activity is mediated through binding with Trk receptors and p75NTR. Expression of Trk receptors has been reported in the injured rat spinal cord. ${ }^{20,21}$ In particular, although Trk receptor expression is not observed in the lesion zone and decreased in the area surrounding the injury site 1 day after SCI, ${ }^{21}$ expression of truncated TrkB mRNA is increased at 6 weeks after injury, even though expression levels of BDNF mRNA in the spinal cord were quite low. ${ }^{20}$ In addition, TrkB and TrkC mRNA persisted in corticospinal and rubrospinal neurons at similar levels for 42 days after injury. ${ }^{21}$ The maintenance of sufficient Trk receptor expression and NF levels is important in promoting regeneration of spinal cord axons, as a previous study showed that NT-3 treatment combined with neural precursor cell transplants that were ex vivo-engineered to overexpress TrkC increased graft survival and donor cell migration in the host spinal cord. ${ }^{22}$

In addition to the Trk receptors, neurotrophins also bind to p75NTR, and a proneurotrophin form mediates a proapoptotic effect through p75NTR signaling. ${ }^{23}$ p75NTR mRNA expression is not present in the intact adult spinal cord but is observed 6 hours, 1 day, and 6 weeks after a thoracic-level SCI. ${ }^{20}$ Binding of the proneurotrophin form of NGF or BDNF to the p75NTR without Trk signaling triggers apoptosis during development and following injury, ${ }^{23}$ and prevention of this binding may thus protect against cell death after SCI. MNTs that do not bind the p75NTR have been generated, and their effects on the survival of SCs and growth of axons in an animal model of SCI model have been evaluated. ${ }^{15}$

Recently, in addition to the neurotrophins, GDNF has been established as another key neuroprotective and regenerative factor in nonhuman animal models of injured or degenerative spinal cord. ${ }^{24,25}$ GDNF binds to the Ret receptors and GDNF family receptor $\alpha(\mathrm{GFR} \alpha)$, increased GDNF-GFR $\alpha 1$ signaling has been shown to promote synaptic formation, ${ }^{26}$ and GFR $\alpha$ mRNA is still expressed around the injury site 6 weeks after contusion of the rat thoracic cord (Enomoto et al, unpublished data, 2013), making the GDNFGFR $\alpha 1$ axis an attractive therapeutic target. SCs have higher endogenous mRNA expression of GDNF than NPCs in vitro (Enomoto et al, unpublished data, 2013), and transplantation of GDNF-overexpressing SCs into the hemisected rat spinal cord results in propriospinal axonal regeneration and synapse formation. ${ }^{27}$ However, NF receptor expression following various types of SCI should be verified to effectively utilize NF signaling for spinal cord regeneration.

\section{Optimization of NFs to enhance regeneration in the injured spinal cord}

Expression of NFs generally increases during the acute phase of SCI but is not maintained in the chronic phase because of cellular damage or loss. For example, BDNF mRNA expression in the spinal cord is increased 1 day after SCI but not 6 weeks post-SCI. ${ }^{20}$ By contrast, NT-3 mRNA expression was not detected at any time after injury and was not found in intact spinal cord. Survival of astrocytes, oligodendrocytes, and microglia in the region of injury is important in increasing NF expression after SCI. ${ }^{28}$ In cell transplantation studies, NF expression is altered in the injured spinal cord after either NPC or BMSC transplantation. However, even with NPC transplantation, BDNF levels were still low 1 week after the transplantation. ${ }^{29}$ The results suggest that alternative routes of administration should be considered to increase NF levels in the region of injury.

Adverse effects of intrathecal NF delivery have been described, ${ }^{30}$ such as weight loss and gait disturbances in sheep that received BDNF, ${ }^{31}$ although widespread effects of intrathecal NGF infusion on neuronal cells were also shown to induce sensory and sympathetic fiber sprouting in the spinal cord of rats and monkeys. ${ }^{30}$

Given these adverse effects and the difficulty in achieving effective NF levels, together with recent progress in the safe 
use of viral vectors, targeted gene delivery could be used to overexpress NFs via direct injection into the injured spinal cord..$^{30} \mathrm{~A}$ number of vectors, such as lentiviral, adenoviral, and retroviral vectors, have been used in transduction of genes into the spinal cord. ${ }^{32}$ Rapid downregulation of transgene expression is observed with retroviral gene delivery, but lentivirus provides stable transgene expression in the spinal cord for up to 4 weeks with minimal inflammatory responses, suggesting therapeutic potential. Such an approach, combined with NF-secreting cells, may be particularly useful in building a cellular bridge connecting the proximal and distal stumps of the transected spinal cord, ${ }^{1}$ where the regenerating nerve fibers grow into an implanted synthetic tube seeded with in vitro-expanded cells originating from either central or peripheral nervous system tissues. SCs are particularly attractive for such an approach because they can be easily isolated from peripheral nerves. ${ }^{33,34}$ In a previous study, SC transplantation combined with local infusion of both BDNF and NT-3 into the transected spinal cord resulted in twice the number of myelinated axons compared to SC transplantation alone, whereas infusion of BDNF and NT-3 alone, without cell transplantation, did not result in any regeneration of axons into the region of injury. ${ }^{35}$ Therefore, SC transplantation increases axonal regeneration and myelination of the regenerated axons. In vitro-expanded SCs have also been genetically modified to express multifunctional neurotrophins such as D15A, which binds to and activates TrkB, TrkC, and p75NTR. ${ }^{7}$ D15A-expressing SCs have also been shown to survive and promote axonal regeneration in the injured spinal cord. ${ }^{15-19}$ A number of studies have utilized transplantation of neural and glial progenitors expressing D15A. ${ }^{36-39}$ The results of these studies are summarized in Table 1.

\section{Engineering of MNTs for SC transplantation studies}

The multifunctional neurotrophins D15A and MNT-1 signal through TrkB, TrkC, and p75NTR and through TrkA, TrkB, TrkC, and p75NTR, respectively. ${ }^{7}$ The BDNF- and NT-3mimicking effects of D15A on Trk receptors are useful in increasing the regeneration of descending fibers after SCI, but increased p75NTR signaling has proapoptotic effects and results in cell death though Rho activation. ${ }^{40}$ Therefore, to reduce p75NTR affinity while preserving Trk signaling, mutant MNTs were generated, and their effects on axonal growth were evaluated in vitro and in an SCI model. ${ }^{15}$ Because Tyr-11 (Y11), Arg-68 (R68), Arg-87 (R87), Arg-114 (R114), and Lys-115 (K115) have been previously identified as important binding determinants for $\mathrm{p} 75 \mathrm{NTR},{ }^{7,41,42}$ all of these residues were mutated to alanine in human D15A (Figure 1A). To obtain an MNT with the lowest affinity to p75NTR, concentration levels of NT-3 were analyzed by enzyme-linked immunosorbent assay in conditioned medium from HEK293 cells transfected with different mutations. NT-3 secretion was not observed on transfection of MNTs with alanine residues at positions Y51 (R103/Y51A), R68 (p75-22, p75-23), or R87 (p75-21, p75-24, p75-25) (Figure 1B), suggesting that these residues are critical for processing and secretion. Similar to a previous study, ${ }^{7} \mathrm{D} 15 \mathrm{~A} /$ R103A was secreted more efficiently than D15A (Figure 1B). Furthermore, an in vitro axonal growth assay was performed by applying supernatants containing D15A, D15A/R103A, or D15A/p75-2 to embryonic dorsal root ganglion (DRG) explants, in which axonal growth is dependent on NT-3, BDNF, and p75NTR. D15A/R103A and D15A/p75-2 treatment resulted in decreased neurite outgrowth from the explant compared to D15A (Figure 2A), indicating that the explants require p75NTR activity for optimal neurite outgrowth. In vitro-expanded SCs transduced with MNT-encoding lentiviruses were also transplanted into injured spinal cords for in vivo evaluation. The SCs were co-transduced with lentiviruses encoding GFP to enable determination of donor cell fate. A significant increase of D15A/p75-2 was observed in SCI animals that received the transplant (Figure 2B). SCs are known to sustain their own survival by growth factor secretion through autocrine mechanisms. ${ }^{43}$ Thus, decreased affinity of the proMNT form to p75NTR could be in part responsible for the enhanced survival of SCs in the injured spinal cord. Thus, this mechanism may be beneficial for in vivo transplantation, in contrast to the neurite outgrowth that results in vitro. However, animals transplanted with SCs expressing D15A/R103A showed significantly higher cavity volumes, possibly because D15A/R103A proMNT secreted by the SCs increased endogenous p75NTR signaling, which has been shown to induce SC death in vitro and after axotomy. ${ }^{44}$ Additionally, animals transplanted with SCs expressing D15A/p75-2 did not show improvement of motor function compared to control animals or animals transplanted with SCs expressing D15A. Thus, even though expression of mutant D15A with reduced p75NTR affinity by transplanted SCs increased their survival and myelination in the lesion, additional strategies are necessary to prevent degeneration and promote the regeneration of descending axons to effectively provide functional recovery. As an example of such a strategy, D15A-expressing SCs were transplanted into rats with a contused spinal cord. Rats were simultaneously treated with systemic rolipram (a phosphodiesterase-4 inhibitor), to 


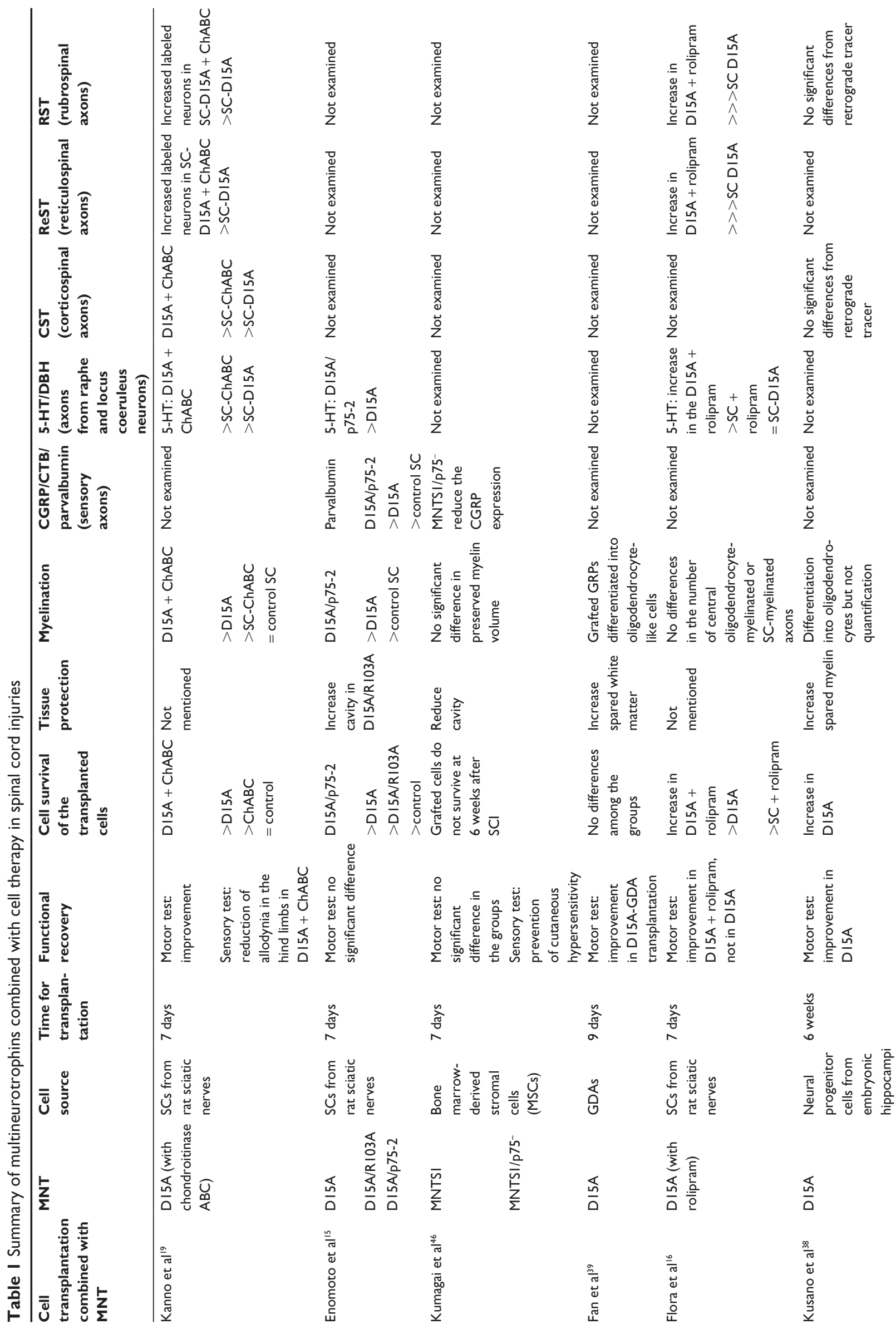


increase cAMP signaling, ${ }^{16}$ and below-level motor function was observed over time. SC transplantation has also been supplemented by administration of chondroitinase ABC (ChABC), which is an enzyme that cleaves glycosaminoglycan side chains, ${ }^{19}$ as ChABC has been reported to be useful for overcoming the inhibitory influence of CSPGs on axonal growth in the injured spinal cord. ${ }^{45}$ The combination of ChABC and SCs resulted in significant improvement of motor function and attenuation of sensory disorders such as hind paw mechanical and thermal allodynia. From a clinical perspective, SCs are advantageous because they are available as autologous cells from SCI patients; thus far, only monotherapeutic transplantation trials have been planned, but combination strategies such as those described earlier may be implemented depending on the preclinical results in experimental models.

\section{Transplantation of other cell types expressing MNTs}

Reports of transplantation of MNT-expressing cells are summarized in Table 1. Transplanted glial-restricted precursor cells (GRPs) or GRP-derived astrocytes expressing D15A integrate well into the host spinal cord, express myelin markers, and improve motor function..$^{37,39} \mathrm{D} 15 \mathrm{~A}$-expressing NPCs were transplanted into the injured spinal cord, ${ }^{38}$ and even during the chronic phase of SCI, the D15A-NPC transplants provided partial recovery of hind limb function. In contrast to SCs isolated from the adult sciatic nerve, GRPs and NPCs were isolated from embryonic spinal cord and brain, thus capable of extensive cell migration and differentiation into oligodendrocytes in the host spinal cord. MSCs, particularly bone marrow MSCs (BMSCs), are currently available as candidate autologous cells, similar to SCs. MSCs were genetically engineered to express MNTS1, a multifunctional neurotrophin that binds to TrkA, TrkB, TrkC, and p75NTR, or MNTS1/p75-, in which both R113 and K114 were mutated to reduce binding to $\mathrm{p} 75 \mathrm{NTR},{ }^{7}$ for transplantation into an experimental SCI model. ${ }^{46}$ Transplantation of MNTS1/p75-expressing MSCs into contused rat spinal cord promoted angiogenesis and mitigated glial scar formation while enabling the preservation and/or regeneration of NFM-positive axons $4 \mathrm{~mm}$ rostral to the lesion epicenter and also at the lesion epicenter itself. The reduction of p75NTR activation may have contributed to angiogenesis because p75NTR is involved in endothelial cell apoptosis. ${ }^{47}$ Collectively, in vivo transplantation of MSCs expressing MNTS1 and MNTS1/p75- and SCs expressing D15A/p75-2 shows that both increased Trk receptor activation and decreased p75NTR signaling can be utilized to improve SCI-induced 
A

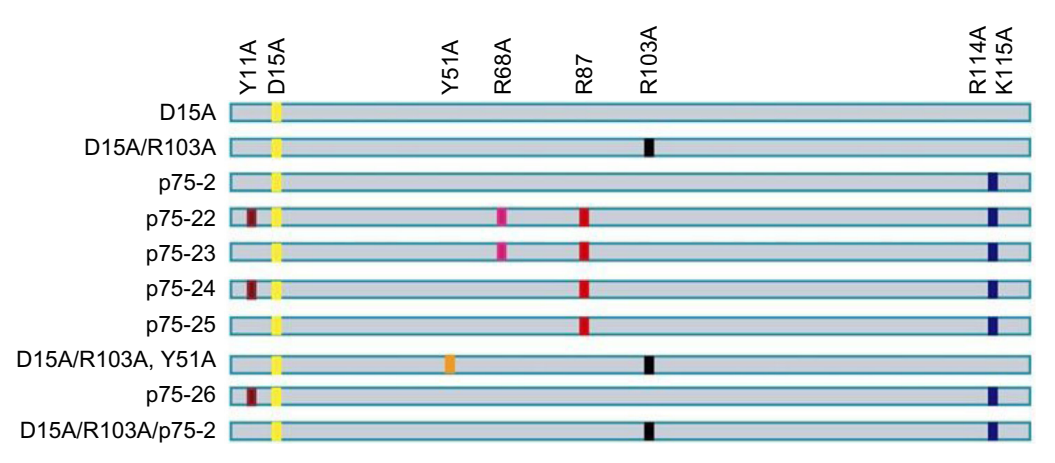

B

Secretion (\% of D15A)

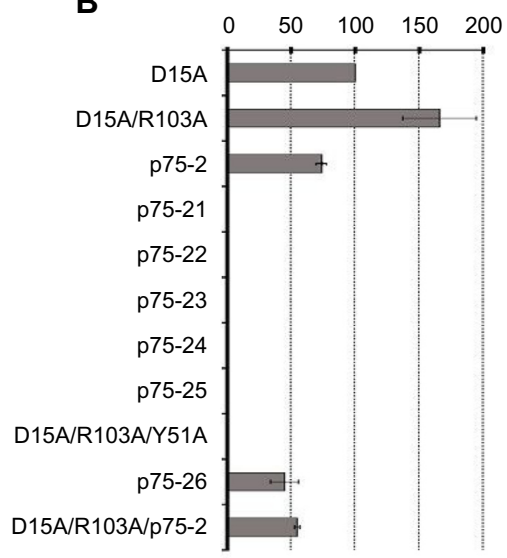

Figure I Characterization of DI5A MNT variants.

Notes: (A) Mutant neurotrophins were constructed. p75-2 denotes the RII4A/KII5A mutation. p75-22 denotes the YIIA/R68A/R87A/RII4A/KII5A mutation. P7523 denotes the R68A/R87A/RII4A/KII5A mutation. p75-24 denotes the YII/R87A/RII4A/KII5A mutation. p75-25 denotes the R87A/R I I4A/KII5A mutation. P75-26 denotes the YIIA/RII4A/KII5A mutation. (B) ELISA analysis. An anti-NT-3 antibody was used to evaluate the conditioned medium from HEK293 cells expressing the DI5A mutants. Data points represent the mean \pm SEM. Adapted from Exp Neurol, 248, Enomoto M, Bunge MB, Tsoulfas P. A multifunctional neurotrophin with reduced affinity to p75NTR enhances transplanted Schwann cell survival and axon growth after spinal cord injury, I70-182. Copyright (2013) with permission from Elsevier.

Abbreviations: MNT, multineurotrophin; ELISA, enzyme-linked immunosorbent assay; SEM, standard error of the mean.

motor deficits. Future studies will need to elucidate the mechanism underlying the interaction between Trk and p75NTR in the SCI setting.

\section{Conclusion}

In this overview of studies on spinal cord regeneration using NFs and MNTs, we review the literatures that MNTs

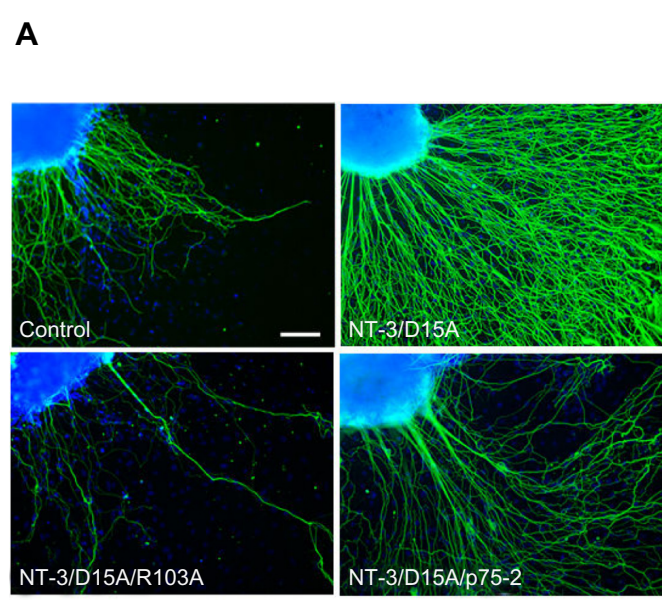

delivered by cell therapy provide tissue protection and axonal regeneration in the injured spinal cord while at the same time enhancing donor cell survival, thereby enabling functional recovery. MNTs are particularly advantageous because a single molecule, rather than several neurotrophins, is utilized to simultaneously induce regeneration of multiple fiber tracts, angiogenesis, and tissue protection. In particular, D15A
B
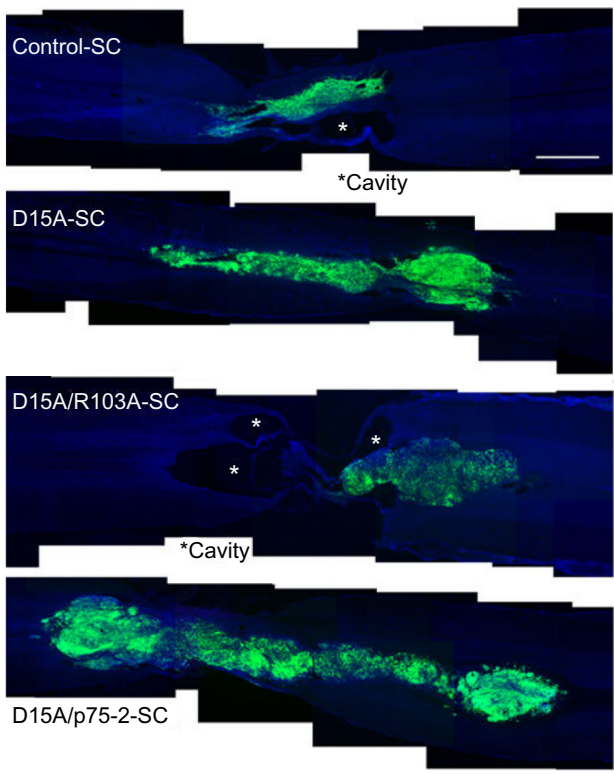

Figure 2 Evaluation of different DI5A MNT variants in vitro and in vivo.

Notes: (A) Biological assay of neurite outgrowth induced by MNT variants. Immunocytochemical staining of the neuronal marker Tuj I (green) with DAPI counterstaining of cell nuclei (blue) in EI5 rat DRG explants. The DRG explants were grown for 4 days in the presence of mock-transduced conditioned medium (control) and conditioned medium from cells expressing DI5A, DI5A/RI03A, or DI5A/p75-2. Scale bar $500 \mu \mathrm{m}$. (B) Survival of GFP-expressing SCs in injured rat spinal cord. SCs expressing MNT variants and GFP were transplanted into contused spinal cords. Photomicrographs of representative horizontal sections are shown 6 weeks after transplantation. Cavities $(*)$ were observed in rats that received cells expressing DI5A/RI03A. SCs expressing DI5A/p75-2 with reduced p75NTR-binding affinity significantly increased the number of GFP-positive cells in the host spinal cord. Scale bar I mm. Adapted from Exp Neurol, 248, Enomoto M, Bunge MB, Tsoulfas P. A multifunctional neurotrophin with reduced affinity to p75NTR enhances transplanted Schwann cell survival and axon growth after spinal cord injury, 170-182. Copyright (20I3) with permission from Elsevier. Abbreviations: MNT, multineurotrophin; DAPI, 4',6-diamidino-2-phenylindole; DRG, dorsal root ganglion; SCs, Schwann cells; GFP, green fluorescent protein. 
has shown definitive regenerative activity in corticospinal or rubrospinal axons, and further tests of D15A/p 75-2 and MNTS1/p75- have demonstrated motor recovery. However, there are limitations associated with potential therapeutic application of genetically modified cell lines. First, it is possible that continuous release of NFs or MNTs by genetically modified cells could lead to increased proliferative activity and implant size within the host tissue. However, release over time appears to be reduced - production of D15A was decreased by $20 \% 6$ weeks after transplantation of lentivirusinduced SCs compared to 2 days after transplantation. ${ }^{17}$ In general, the survival rate of transplanted cells is low, and their ability to self-sustain is limited. Further development of methods to detect transplanted cells or modified vectors in vivo will be necessary to control cell survival after the transplantation. Recently, migration of magnetically labeled transplanted stem cells could be detected by magnetic resonance imaging in host brain tissue.$^{48}$ Second, lentiviral vectors are considered to be relatively safe, but alternatives to viral vectors should be considered for sustained production of NFs and MNTs. Nonviral gene delivery systems, whereby plasmid DNA is delivered by hydrodynamic injection, cationic liposomes, nanoparticles, or lipid conjugation, may offer the potential of safe genetic engineering with minimal side effects, although these methodologies are typically associated with low transfection efficiency and transient transgene expression. Additionally, to achieve functional motor recovery, it may be necessary to combine the cellular approach with pharmacotherapeutics such as ChABC or rolipram. However, with the selection of the appropriate cell source and NFs or MNTs and their delivery method, it may be possible to restore lost function in SCI patients.

\section{Acknowledgments}

This work was supported in part by the Ministry of Health, Labour, and Welfare Sciences Research Grant, a Grant-in-Aid for Scientific Research (C) from the Japan Society for the Promotion of Science, and a Grant-in-Aid from the General Insurance Association of Japan. The author is grateful to Prof K Shinomiya (Yokohama City Minato Red Cross Hospital), Prof A Okawa (Tokyo Medical and Dental University), and Dr P Tsoulfas (The Miami Project to Cure Paralysis) for their advice and generous support. The author thanks Dr K Fukushima, Dr F Numano, Dr K Kusano, Dr T Hirai, Dr M Onuma-Ukegawa, and Dr H Kaburagi for their continuous support for his research in SCI.

\section{Disclosure}

The author reports no conflicts of interest in this work.

\section{References}

1. Jones LL, Oudega M, Bunge MB, Tuszynski MH. Neurotrophic factors, cellular bridges and gene therapy for spinal cord injury. J Physiol. 2001;533(Pt 1):83-89.

2. Grill RJ, Blesch A, Tuszynski MH. Robust growth of chronically injured spinal cord axons induced by grafts of genetically modified NGF-secreting cells. Exp Neurol. 1997;148(2):444-452.

3. Kobayashi NR, Fan DP, Giehl KM, Bedard AM, Wiegand SJ, Tetzlaff W. BDNF and NT-4/5 prevent atrophy of rat rubrospinal neurons after cervical axotomy, stimulate GAP-43 and Talpha1-tubulin mRNA expression, and promote axonal regeneration. J Neurosci. 1997;17(24):9583-9595.

4. Bradbury EJ, Khemani S, Von R, King, Priestley JV, McMahon SB. NT-3 promotes growth of lesioned adult rat sensory axons ascending in the dorsal columns of the spinal cord. Eur J Neurosci. 1999;11(11):3873-3883.

5. Hiebert GW, Khodarahmi K, McGraw J, Steeves JD, Tetzlaff W. Brainderived neurotrophic factor applied to the motor cortex promotes sprouting of corticospinal fibers but not regeneration into a peripheral nerve transplant. J Neurosci Res. 2002;69(2):160-168.

6. Sayer FT, Oudega M, Hagg T. Neurotrophins reduce degeneration of injured ascending sensory and corticospinal motor axons in adult rat spinal cord. Exp Neurol. 2002;175(1):282-296.

7. Urfer R, Tsoulfas P, Soppet D, Escandón E, Parada LF, Presta LG. The binding epitopes of neurotrophin-3 to its receptors trkC and gp75 and the design of a multifunctional human neurotrophin. EMBO J. 1994;13(24):5896-5909.

8. Ruozi B, Belletti D, Bondioli L, et al. Neurotrophic factors and neurodegenerative diseases: a delivery issue. Int Rev Neurobiol. 2012;102:207-247.

9. Mothe AJ, Tator $\mathrm{CH}$. Advances in stem cell therapy for spinal cord injury. J Clin Invest. 2012;122(11):3824-3834.

10. Ruff CA, Wilcox JT, Fehlings MG. Cell-based transplantation strategies to promote plasticity following spinal cord injury. Exp Neurol. 2012;235(1):78-90.

11. Azari MF, Mathias L, Ozturk E, Cram DS, Boyd RL, Petratos S. Mesenchymal stem cells for treatment of CNS injury. Curr Neuropharmacol. 2010;8(4):316-323.

12. Fehlings MG, Vawda R. Cellular treatments for spinal cord injury: the time is right for clinical trials. Neurotherapeutics. 2011;8(4):704-720.

13. Murray M, Kim D, Liu Y, Tobias C, Tessler A, Fischer I. Transplantation of genetically modified cells contributes to repair and recovery from spinal injury. Brain Res Brain Res Rev. 2002;40(1-3):292-300.

14. Watabe K, Fukuda T, Tanaka J, Honda H, Toyohara K, Sakai O. Spontaneously immortalized adult mouse Schwann cells secrete autocrine and paracrine growth-promoting activities. J Neurosci Res. 1995;41(2):279-290.

15. Enomoto M, Bunge MB, Tsoulfas P. A multifunctional neurotrophin with reduced affinity to p75NTR enhances transplanted Schwann cell survival and axon growth after spinal cord injury. Exp Neurol. 2013;248:170-182.

16. Flora G, Joseph G, Patel S, et al. Combining neurotrophin-transduced schwann cells and rolipram to promote functional recovery from subacute spinal cord injury. Cell Transplant. 2013;22(12):2203-2217.

17. Golden KL, Pearse DD, Blits B, et al. Transduced Schwann cells promote axon growth and myelination after spinal cord injury. Exp Neurol. 2007;207(2):203-217.

18. Hurtado A, Moon LD, Maquet V, Blits B, Jérôme R, Oudega M. Poly (D,L-lactic acid) macroporous guidance scaffolds seeded with Schwann cells genetically modified to secrete a bi-functional neurotrophin implanted in the completely transected adult rat thoracic spinal cord. Biomaterials. 2006;27(3):430-442.

19. Kanno H, Pressman Y, Moody A, et al. Combination of engineered Schwann cell grafts to secrete neurotrophin and chondroitinase promotes axonal regeneration and locomotion after spinal cord injury. J Neurosci. 2014;34(5):1838-1855.

20. Widenfalk J, Lundströmer K, Jubran M, Brene S, Olson L. Neurotrophic factors and receptors in the immature and adult spinal cord after mechanical injury or kainic acid. J Neurosci. 2001;21(10):3457-3475. 
21. Liebl DJ, Huang W, Young W, Parada LF. Regulation of Trk receptors following contusion of the rat spinal cord. Exp Neurol. 2001;167(1):15-26.

22. Castellanos DA, Tsoulfas P, Frydel BR, Gajavelli S, Bes JC, Sagen J. TrkC overexpression enhances survival and migration of neural stem cell transplants in the rat spinal cord. Cell Transplant. 2002;11(3):297-307.

23. Teng KK, Felice S, Kim T, Hempstead BL. Understanding proneurotrophin actions: recent advances and challenges. Dev Neurobiol. 2010;70(5):350-359.

24. Allen SJ, Watson JJ, Shoemark DK, Barua NU, Patel NK. GDNF, NGF and BDNF as therapeutic options for neurodegeneration. Pharmacol Ther. 2013;138(2):155-175.

25. Awad BI, Carmody MA, Steinmetz MP. Potential role of growth factors in the management of spinal cord injury. World Neurosurg. 2015;83(1):120-131.

26. Ledda F, Paratcha G, Sandoval-Guzmán T, Ibáñez CF. GDNF and GFRalpha1 promote formation of neuronal synapses by ligand-induced cell adhesion. Nat Neurosci. 2007;10(3):293-300.

27. Deng LX, Deng P, Ruan Y, et al. A novel growth-promoting pathway formed by GDNF-overexpressing Schwann cells promotes propriospinal axonal regeneration, synapse formation, and partial recovery of function after spinal cord injury. J Neurosci. 2013;33(13):5655-5667.

28. Dougherty KD, Dreyfus CF, Black IB. Brain-derived neurotrophic factor in astrocytes, oligodendrocytes, and microglia/macrophages after spinal cord injury. Neurobiol Dis. 2000;7(6 Pt B):574-585.

29. Hawryluk GW, Mothe A, Wang J, Wang S, Tator C, Fehlings MG. An in vivo characterization of trophic factor production following neural precursor cell or bone marrow stromal cell transplantation for spinal cord injury. Stem Cells Dev. 2012;21(12):2222-2238.

30. Hendriks WT, Ruitenberg MJ, Blits B, Boer GJ, Verhaagen J. Viral vector-mediated gene transfer of neurotrophins to promote regeneration of the injured spinal cord. Prog Brain Res. 2004;146:451-476.

31. Dittrich F, Ochs G, Grosse-Wilde A, et al. Pharmacokinetics of intrathecally applied BDNF and effects on spinal motoneurons. Exp Neurol. 1996;141(2):225-239.

32. Abdellatif AA, Pelt JL, Benton RL, et al. Gene delivery to the spinal cord: comparison between lentiviral, adenoviral, and retroviral vector delivery systems. $J$ Neurosci Res. 2006;84(3):553-567.

33. Morrissey TK, Kleitman N, Bunge RP. Isolation and functional characterization of Schwann cells derived from adult peripheral nerve. J Neurosci. 1991;11(8):2433-2442.

34. LeviAD, Bunge RP, Lofgren JA, et al. The influence of heregulins on human Schwann cell proliferation. J Neurosci. 1995;15(2):1329-1340.

35. Xu XM, Guénard V, Kleitman N, Aebischer P, Bunge MB. A combination of BDNF and NT-3 promotes supraspinal axonal regeneration into Schwann cell grafts in adult rat thoracic spinal cord. Exp Neurol. 1995;134(2):261-272.
36. Blits B, Kitay BM, Farahvar A, Caperton CV, Dietrich WD, Bunge MB. Lentiviral vector-mediated transduction of neural progenitor cells before implantation into injured spinal cord and brain to detect their migration, deliver neurotrophic factors and repair tissue. Restor Neurol Neurosci. 2005;23(5-6):313-324.

37. Cao Q, Xu XM, Devries WH, et al. Functional recovery in traumatic spinal cord injury after transplantation of multineurotrophin-expressing glial-restricted precursor cells. J Neurosci. 2005;25(30):6947-6957.

38. Kusano K, Enomoto M, Hirai T, et al. Transplanted neural progenitor cells expressing mutant NT3 promote myelination and partial hind limb recovery in the chronic phase after spinal cord injury. Biochem Biophys Res Commun. 2010;393(4):812-817.

39. Fan C, Zheng Y, Cheng X, et al. Transplantation of D15A-expressing glial-restricted-precursor-derived astrocytes improves anatomical and locomotor recovery after spinal cord injury. Int J Biol Sci. 2013;9(1):78-93.

40. Dubreuil CI, Winton MJ, McKerracher L. Rho activation patterns after spinal cord injury and the role of activated Rho in apoptosis in the central nervous system. J Cell Biol. 2003;162(2):233-243.

41. Gong Y, Cao P, Yu HJ, Jiang T. Crystal structure of the neurotrophin-3 and p75NTR symmetrical complex. Nature. 2008;454(7205):789-793.

42. He XL, Garcia KC. Structure of nerve growth factor complexed with the shared neurotrophin receptor p75. Science. 2004;304(5672):870-875.

43. Mirsky R, Jessen KR. The neurobiology of Schwann cells. Brain Pathol. 1999;9(2):293-311.

44. Syroid DE, Maycox PJ, Soilu-Hänninen M, et al. Induction of postnatal schwann cell death by the low-affinity neurotrophin receptor in vitro and after axotomy. J Neurosci. 2000;20(15):5741-5747.

45. Bradbury EJ, Moon LD, Popat RJ, et al. Chondroitinase ABC promotes functional recovery after spinal cord injury. Nature. 2002;416(6881):636-640.

46. Kumagai G, Tsoulfas P, Toh S, McNiece I, Bramlett HM, Dietrich WD. Genetically modified mesenchymal stem cells (MSCs) promote axonal regeneration and prevent hypersensitivity after spinal cord injury. Exp Neurol. 2013;248:369-380.

47. Caporali A, Pani E, Horrevoets AJ, et al. Neurotrophin p75 receptor (p75NTR) promotes endothelial cell apoptosis and inhibits angiogenesis: implications for diabetes-induced impaired neovascularization in ischemic limb muscles. Circ Res. 2008;103(2):e15-e26.

48. Ngen EJ, Wang L, Kato Y, et al. Imaging transplanted stem cells in real time using an MRI dual-contrast method. Sci Rep. 2015;5:13628.
Journal of Neurorestoratology

\section{Publish your work in this journal}

The Journal of Neurorestoratology is an international, peer-reviewed, open access online journal publishing original research and review articles on the subject of Neurorestoratology. To provide complete coverage of this revolutionary field the Journal of Neurorestoratology will report on relevant experimental research, technological advances, and

\section{Dovepress}

clinical achievements. The manuscript management system is completely online and includes a very quick and fair peer-review system, which is all easy to use. Visit http://www.dovepress.com/testimonials.php to read real quotes from published authors. 